University of Nebraska - Lincoln

DigitalCommons@University of Nebraska - Lincoln

$10-10-2018$

\title{
A tale of three kingdoms: members of the Phylum Nematoda independently acquired the detoxifying enzyme cyanase through horizontal gene transfer from plants and bacteria
}

Dante Zarlenga

M. Mitreva

P. Thompson

R. Tyagi

W. Tuo

See next page for additional authors

Follow this and additional works at: https://digitalcommons.unl.edu/usdaarsfacpub

This Article is brought to you for free and open access by the U.S. Department of Agriculture: Agricultural Research Service, Lincoln, Nebraska at DigitalCommons@University of Nebraska - Lincoln. It has been accepted for inclusion in Publications from USDA-ARS / UNL Faculty by an authorized administrator of DigitalCommons@University of Nebraska - Lincoln. 
Authors

Dante Zarlenga, M. Mitreva, P. Thompson, R. Tyagi, W. Tuo, and E.P. Hoberg 
Parasitology

cambridge.org/par

\section{Research Article}

Cite this article: Zarlenga DS, Mitreva M, Thompson P, Tyagi R, Tuo W, Hoberg EP (2019). A tale of three kingdoms: members of the Phylum Nematoda independently acquired the detoxifying enzyme cyanase through horizontal gene transfer from plants and bacteria. Parasitology 146, 445-452. https:// doi.org/10.1017/S0031182018001701

Received: 23 July 2018

Revised: 31 August 2018

Accepted: 10 September 2018

First published online: 10 October 2018

\section{Key words:}

Cyanase; evolution; horizontal gene transfer; nematode; parasitism; Trichinella

Author for correspondence:

D. S. Zarlenga,

E-mail: Dante.zarlenga@ars.usda.gov

\section{A tale of three kingdoms: members of the Phylum Nematoda independently acquired the detoxifying enzyme cyanase through horizontal gene transfer from plants and bacteria}

\author{
D. S. Zarlenga ${ }^{1}$, M. Mitreva ${ }^{2}$, P. Thompson ${ }^{1}$, R. Tyagi ${ }^{2}$, W. Tuo ${ }^{1}$ and E. P. Hoberg ${ }^{1}$
}

${ }^{1}$ USDA, Agricultural Research Service, Animal Parasitic Diseases Lab, Beltsville, MD 20705 USA and ${ }^{2}$ The Genome Institute, Washington University School of Medicine, St. Louis, MO 63108, USA

\begin{abstract}
Horizontal gene transfer (HGT) has played an important role in the evolution of nematodes. Among candidate genes, cyanase, which is typically found only in plants, bacteria and fungi, is present in more than 35 members of the Phylum Nematoda, but absent from free-living and clade V organisms. Phylogenetic analyses showed that the cyanases of clade I organisms Trichinella spp., Trichuris spp. and Soboliphyme baturini (Subclass: Dorylaimia) represent a well-supported monophyletic clade with plant cyanases. In contrast, all cyanases found within the Subclass Chromadoria which encompasses filarioids, ascaridoids and strongyloids are homologous to those of bacteria. Western blots exhibited typical multimeric forms of the native molecule in protein extracts of Trichinella spiralis muscle larvae, where immunohistochemical staining localized the protein to the worm hypodermis and underlying muscle. Recombinant Trichinella cyanase was bioactive where gene transcription profiles support functional activity in vivo. Results suggest that: (1) independent HGT in parasitic nematodes originated from different Kingdoms; (2) cyanase acquired an active role in the biology of extant Trichinella; (3) acquisition occurred more than 400 million years ago (MYA), prior to the divergence of the Trichinellida and Dioctophymatida, and (4) early, free-living ancestors of the genus Trichinella had an association with terrestrial plants.
\end{abstract}

U.S. government works are not subject to copyright.

(c) Cambridge University Press 2018

\section{Introduction}

Horizontal gene transfer (HGT) involves the asexual movement of genetic material between disparate organisms and, in the process, the acquisition of traits typically absent from the inheriting organism. HGT has played a prominent role in the evolution of bacteria (Polz et al., 2013). Estimates as high as $81 \%$ have been proposed as the average number of prokaryotic genes involved at some point in HGT (Dagan et al., 2008). However, the importance of HGT in the evolution of eukaryotes remains in flux. As early as 1998, Keen and Roberts (1998) hypothesized a relationship between the ability of nematodes to parasitize plants and the acquisition of genes from soil bacteria to facilitate that process. With the advance of genomics studies, HGT has been better implicated in the evolution of parasitism in plant nematodes (Mitreva et al., 2009; Haegeman et al., 2011). Since that time, the database of putatively transferred genes in plant and free-living nematodes has increased substantially.

Habitat and opportunity have profound impacts on the potential for HGT, which is well documented in endosymbiotic relationships. However, HGT also occurs when there is a simple facultative, environmental association. Genome analysis of the necromenic nematode Pristionchus pacificus revealed functional cellulase genes of bacterial origin (Dieterich et al., 2008). Further, Rödelsperger and Sommer (2011) demonstrated that P. pacificus diapausin genes, typically associated with insects, were likely acquired via HGT from its necromenic associations with beetles. Consequently, evidence is mounting that HGT is not only common in the evolution of bacteria and in gene transmission between prokaryotes and eukaryotes, but also in the movement of functional genes between higher order organisms (Andersson, 2005; Richards et al., 2006; Keeling and Palmer, 2008).

Cyanase (cyanate hydratase; cyanate hydrolase; cyanate lyase) is an enzyme that catalyses bicarbonate-dependent degradation of cyanate to ammonia and carbon dioxide. Enzyme functionality is predicated on the formation of dimers which assemble into decamers; however, the active site is produced from residues of four adjacent subunits within the homodecamer (Walsh et al., 2000). Given that its presence is well disseminated among the ancestral lineages in the tree of life, it has been postulated that cyanase played a role in early evolution and the detoxification of environmental as well as metabolically generated cyanate (Ebbs, 2004). In marine cyanobacteria, cyanase was originally thought only to detoxify cyanate produced from intracellular urea and/or carbamoyl phosphate (CP) decomposition; however, in more recent studies (Espie et al., 2007; Maeda and Omata, 2009; Kamennaya and Post, 2013), cyanase was found to be equally important in the generation of nitrogen from externally acquired cyanate for the growth and development of cyanobacteria. 
In a recent study (Zarlenga et al., 2016), we used comparative genomics to investigate parasitism and adaptation within the clade I parasite Trichinella spiralis and identified a putative cyanase gene. Organisms of the genus Trichinella complete their life cycles within a single host and therefore have no free-living stages. Historically, cyanase has been linked only to organisms of plant, bacterial and fungal origins. However, recently, it has been found in insects (Wybouw et al., 2012, 2014) and nematodes (Opperman et al., 2008; Haegeman et al., 2011; Zarlenga et al., 2016), though its activity in nematodes has not been validated. Herein, we tested and validated functional activity of the cyanase gene present in T. spiralis. We further hypothesize independent origins for the cyanase found in clade I nematodes of the genera Trichinella, Trichuris and Soboliphyme relative to the cyanase found in other nematode groups. Results are discussed in the context of HGT, parasitism and functional repurposing of acquired genes.

\section{Materials and methods}

\section{Parasite propagation and isolation}

Swiss-Webster mice were infected orally with 500 muscle larvae (ML) of T. spiralis (ISS 4). Approximately 30 days post infection, ML were isolated from pepsin: $\mathrm{HCl}$ digestions of eviscerated carcasses as described previously (Zarlenga et al., 2002). Crude worm extract (CWE) was produced by homogenizing ML in phosphate-buffered saline (PBS), followed by centrifugation to remove debris. Adult worms and newborn larvae (NBL) were isolated essentially as described by Marti et al. (1987). Adult worms and NBL were each deemed $>90 \%$ pure by microscopic examination. All animals were utilized and treated in accordance with an Animal Use Protocol (\#15-003) approved through the Agricultural Research Service.

\section{RNA isolation, cloning and PCR}

Approximately $300 \mu \mathrm{l}$ of settled ML (350000 ML) were used for the purification of total RNA by proteinase K: SDS digestion, organic extraction and ethanol precipitation (Dame et al., 1987). Total RNA was isolated from NBL using Trizol Reagent (Invitrogen, Thermo Fisher, Carlsbad, CA, USA) (Zarlenga et al., 2002). RNA from adult worms remaining after culture and substantially devoid of NBL were also isolated by homogenizing in Trizol reagent. All RNA samples were treated with DNAse, followed by organic extraction and ethanol precipitation prior to cDNA synthesis.

Complementary DNA was synthesized at $42{ }^{\circ} \mathrm{C}$ using Superscript II reverse transcriptase (Invitrogen, Thermo Fisher), oligo $\mathrm{dT}$ primer and $5 \mu \mathrm{g}$ of isolated RNA in a volume of $40 \mu \mathrm{l}$. The resultant cDNA was enzymatically amplified $\left(94^{\circ} \mathrm{C} 30 \mathrm{~s} ; 60^{\circ} \mathrm{C}\right.$ $30 \mathrm{~s} ; 72^{\circ} \mathrm{C} 2 \mathrm{~min} ; \times 35$ cycles) using ExTAQ DNA polymerase and cyanase-specific forward (\#1440)

(5'-aaggatccgatgtcggtggtgtttagatt) and reverse (\#1441) (5'-aaggtcgacctaatccagctgggttggt) primers complementary to the $5^{\prime}$ and $3^{\prime}$ ends of the gene, respectively. The primers contained Bam HI and Sal I restriction sites, respectively (underlined) for subsequent cloning for protein expression. The resultant product was cloned into the TA cloning vector TOPO Cr2.1 (Invitrogen, Thermo Fisher), according to the manufacturer's instructions, and used to transform Escherichia coli cells (DH5 $\alpha$ strain). Clones were validated by colony PCR (Nishikawa et al., 1989) and five were chosen for plasmid isolation and DNA sequencing. At least one clone, Tscyn-1(c13), exhibited $100 \%$ identity with the genomic DNAderived sequence and was used for cloning and protein expression.

Stage-specific transcription was evaluated using forward (\#1454) (5'-tagcagctacgttgaagcagcttg) and reverse (\#1455) (5'-cattcgaatgacaacgcgtcgttct) cyanase-specific primers under the same conditions as described for cDNA amplification, except that random hexamers were used for cDNA synthesis. The primers targeted a $244 \mathrm{bp}$ fragment within the full-length gene. Small subunit rRNA (cDNA) was amplified as a housekeeping gene using forward (\#46) (5'-gctgaaacttaaaggaattgac) and reverse (\#50) $\left(5^{\prime}\right.$-tcagtgtagcgcgcgtgc) primers. Amplifications were terminated within the linear portion of the amplification curve at 26 and 28 cycles (cyanase) and at 15 cycles (rRNA). Contamination of total RNA with parasite genomic DNA was evaluated by amplifying total RNA prior to reverse transcription with primers \#46 and $\# 50$.

\section{Bacterial expression and purification of cyanase}

DNA constructs were made to generate His-tagged fusion proteins in two different expression vectors; pSUMO (LifeSensors) for high yield and antibody production, and pET28a (Novagen) for functional assays. To produce sufficient protein for antibody production, plasmid Tscyn-1(c13) was restriction enzyme-digested then cloned into the Bam HI/Sal I site of the pSUMO expression vector. One clone, Tscyn-1(c33A), was selected and validated by colony screening (Nishikawa et al., 1989) and DNA sequencing. The expressed product $[\mathrm{rCYN}-1(\mathrm{c} 33 \mathrm{~A})]$ was present only within inclusion bodies and was not biologically functional. Consequently, a second expression construct was made in the Bam $\mathrm{HI} / \mathrm{Sal}$ I site of vector pET28a using primers \#1452 (5'-aatgggtcgcggatcctgtcggtggtgtttagat), \#1453 (5'-ccgcaagcttgtcgacctaatccagctgggttggt) and the In-Fusion HD Cloning Kit as recommended by the manufacturer (Clontech); the underlined bases in primers 1452 and 1453 indicate Bam H1 and Sal I restriction sites, respectively. The resultant construct was transformed into E. coli 'Stellar cells' (Clontech). One clone, Tscyn-1(c94.1), was selected by colony screening (Nishikawa et al., 1989) and exhibited 100\% DNA sequence identity to the parent sequence.

For protein expression, purified plasmid preparations of Tscyn-1(c33A) and Tscyn-1(c94.1) were each transformed into BL21 DE3 cells (Invitrogen, Thermo Fisher). Overnight starter cultures were grown either in $100 \mu \mathrm{g} / \mathrm{mL}$ ampicillin [Tscyn-1 (c33A)] or $50 \mu \mathrm{g} / \mathrm{mL}$ kanamycin [Tscyn-1(c94.1)] and then transferred to $500 \mathrm{~mL}$ of LB containing the appropriate antibiotic. The cells were grown to $\mathrm{OD}_{600}=0.6$, induced in $0.3 \mathrm{~mm}$ isopropyl $\beta$-D-1-thiogalactopyranoside for $5 \mathrm{~h}$, and then centrifuged and treated for $20 \mathrm{~min}$ at $25^{\circ} \mathrm{C}$ in $25 \mathrm{~mL}$ of $100 \mathrm{~mm}$ potassium phosphate buffer $\mathrm{pH} 7.0$, containing $1 \mathrm{mg} / \mathrm{mL}$ lysozyme. The cells were then frozen overnight at $-20^{\circ} \mathrm{C}$.

The next day, both sets of cells were sonicated $3 \times 1 \mathrm{~min}$ $(22$ Watts) and then centrifuged $(25000 \times g)$. To purify recombinant $\mathrm{CYN}-1(\mathrm{c} 33 \mathrm{~A})$ [rCYN-1(c33A)], the pellet was washed three times for $1 \mathrm{~h}$ with $2 \%$ Triton $\mathrm{X}-100$ in $100 \mathrm{~mm}$ potassium phosphate buffer, $\mathrm{pH} 7.2$ (wash buffer), $1 \times$ in $2 \mathrm{M}$ urea + wash buffer and one time in wash buffer. The cleaned inclusion bodies were solubilized in $8 \mathrm{~mL} 6 \mathrm{M}$ guanidinium $\mathrm{HCl}$ overnight with rocking. The liquid was centrifuged and the cleared supernatant was mixed with $8 \mathrm{~mL}$ of a solution containing $20 \mathrm{~mm} \beta$ mercaptoethanol, $500 \mathrm{~mm}$ L-arginine and $500 \mathrm{~mm}$ L-glutamine. The cleared lysate was incubated with $1 \mathrm{~mL}$ (settled volume) of $\mathrm{Ni}$-NTA agarose (Macherey-Nagel) for $4 \mathrm{~h}$ with agitation, loaded on to a column and washed with $300 \mathrm{~mm}$ potassium phosphate containing $20 \mathrm{~mm}$ histidine. Bound protein was eluted with $400 \mathrm{~mm}$ histidine containing $0.3 \%$ sodium lauryl sarcosine (SLS) in wash buffer. The final product was dialysed against $50 \mathrm{~mm}$ potassium phosphate containing $0.2 \%$ SLS. For purifying rCYN-1(c94.1), the cleared lysate from sonicated bacteria was loaded directly onto a Ni-NTA agarose (Macherey-Nagel) column, washed with $300 \mathrm{~mm}$ potassium phosphate buffer, $\mathrm{pH}$ 7.2, and then eluted with $400 \mathrm{~mm}$ histidine in $300 \mathrm{~mm}$ potassium 
phosphate and $0.3 \%$ SLS. The final product was dialysed overnight against $50 \mathrm{~mm}$ potassium phosphate, and then used for activity analyses. Protein concentrations were determined using a BCA Protein Assay kit (Pierce/Thermo Fisher).

\section{In vitro cyanase assay}

Purified rCYN-1(c94.1) was assayed using sodium salicylate (Sigma), sodium nitroferricyanide (Sigma) and hypochlorite in a colorimetric assay for ammonia. A $100 \mu \mathrm{l}$ mixture of $0.8 \mu \mathrm{g}$ of rCYN-1(c94.1), potassium cyanate $(2 \mathrm{~mm})$ and bicarbonate

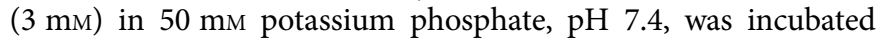
for $30 \mathrm{~min}$ at $42^{\circ} \mathrm{C}$. After incubation, the reaction was supplemented with $50 \mu \mathrm{l}$ of hypochlorite solution $(0.83 \%$ sodium hypochlorite, $0.13 \mathrm{M} \mathrm{NaOH}$ ) and $50 \mu \mathrm{l}$ of catalyst solution $[0.6 \mathrm{M}$ sodium salicylate, $1.34 \mathrm{~mm}$ sodium nitroferricyanide (III), $0.13 \mathrm{M}$ $\mathrm{NaOH}$ ], then incubated an additional $30 \mathrm{~min}$ at $42^{\circ} \mathrm{C}$; colour change was monitored at $\mathrm{OD}_{660}$. Since cyanases are present in most bacterial strains, a negative control-protein preparation was generated from column purified, bacterial lysates derived from an empty vector (pET28a). Enzyme activity was assayed in the presence of increasing concentrations of enzyme, increasing concentrations of sodium chloride $(0-600 \mathrm{~mm})$ and following heat inactivation $\left(10 \mathrm{~min} 95^{\circ} \mathrm{C}\right)$. All reactions were performed in quadruplicate. An ammonia standard was used as a reference.

\section{Western blots and immunohistochemical staining}

Mouse antibodies to purified $\mathrm{rCYN}-1(\mathrm{c} 33 \mathrm{~A})$ were produced as previously described (Zarlenga et al., 2011) with the addition of Emulsigen (MVP technologies) to the antigen/adjuvant mix to a final ratio of $20 \%(\mathrm{v} / \mathrm{v})$. Recombinant proteins and CWE were separated on $8-16 \%$ SDS PAGE gels (Genscript), electrophoretically transferred to immobilon membranes and then blocked for $2 \mathrm{~h}$ in PBS containing $0.1 \%$ Tween-20 and 5\% non-fat dried milk (PBST). Blots were incubated overnight $(16 \mathrm{~h})$ in primary mouse antibody diluted 1:200 in PBST, washed the next day and then incubated for $2 \mathrm{~h}$ in secondary antibody [affinitypurified goat anti-mouse IgG-horseradish peroxidase (HRP)] diluted 1:1000 in PBST. After washing in PBST, blots were stained in 4 chloro-1-naphthol $/ \mathrm{H}_{2} \mathrm{O}_{2}$ solution and photographed.

For immunohistochemical staining, ML were fixed in $10 \%$ neutral formalin for $24 \mathrm{~h}$, embedded in paraffin and sectioned at $5 \mu \mathrm{m}$ (HistoServ Inc., Germantown, MD, USA). Sections were deparaffinized, quenched with $3 \% \mathrm{H}_{2} \mathrm{O}_{2}$ and rehydrated. Antigen-retrieval was conducted by pepsin $(0.4 \%)-\mathrm{HCl}(0.01 \mathrm{~N})$ digestion at $37^{\circ} \mathrm{C}$ for $15 \mathrm{~min}$. The slides were washed twice with $0.75 \%$ Brij 35 in PBS (BRIJ-PBS), blocked with $0.5 \%$ sodium caseinate in BRIJ-PBS for $10 \mathrm{~min}$, and then incubated for $30 \mathrm{~min}$ at room temperature $\left(24^{\circ} \mathrm{C}\right)$ with mouse anti-rCYN-1(c33A) serum (1:800) or with negative control mouse anti-rOos-APY-1 (1:600) (Zarlenga et al., 2011). After washing, goat anti-mouse IgG-HRP (Dako EnVision + System-HRP Labelled Polymer, Agilent) and Dako AEC substrate chromogen (Agilent) were used to detect antibody binding. Tissues were counterstained with haematoxylin, and micrographs were taken using a Zeiss Axioskope 2 Plus microscope and AxioVision software.

\section{Phylogenetic analysis}

Cyanase encoding sequences from 87 representatives of three Kingdoms, Animals (Nematoda), Plants and Eubacteria, were acquired from GenBank (https://www.ncbi.nlm.nih.gov) by independent searches (Supplementary Table S1). Full-length or near full-length amino acid sequences of individual proteins from all available nematodes were selected. A subset of plant and bacteria cyanases was chosen based on the completeness of the sequences and attaining a diverse representation of taxonomic subunits and constrained by best amino acid sequence similarity (BLASTp) matches to nematode queries within each Kingdom. Four of 37 nematode sequences that lacked canonical active site amino acids were not included in the alignment. Protein sequences were aligned using MAFFT, with default parameters as implemented in Geneious v.10.2.3 (BioMatters, Ltd, New Zealand). Following alignment, gaps were removed, leaving 135 homologous amino acids for tree-building. Maximum likelihood trees were built from alignments using PhyML (Guindon et al., 2010). Trees were rooted using the bacterial sequence from Synechococcus, which was closest to the mid-point root of the tree. Of note, all sequences were derived from parasite genomes/transcriptomes. Among the filariods it is not known if these sequences were derived by HGT from Wolbachia endosymbionts or other bacterial sources.

\section{Results}

A gene encoding cyanase in the genus Trichinella was identified in a comparative genome study of T. spiralis with clade III, IV and V parasitic and free-living nematodes (Zarlenga et al., 2016). Phylogenetic analysis of amino acid sequences from currently available nematode cyanases, in conjunction with representative members of the Kingdoms Eubacteria, Plantae and Fungi, is presented in Fig. 1 (non-rooted tree) and Supplementary Fig. S1 (rooted tree). Cyanases from the clade I nematodes (Blaxter, 2011; Blaxter et al., 2014) Trichinella spp., Trichuris spp. and Soboliphyme baturini form a well-supported subclade with plant cyanases that is monophyletic, whereas all other nematode cyanases are in a clade with bacterial cyanases. A paraphyletic sister clade for basal nematodes and plant cyanases is comprised solely of fungal cyanases, which, in turn, is most closely related to cyanases from cyanobacteria. Tree topology was robust to amino acid substitution model (Dayhoff, JTT or BLOSUM62).

Aligning amino acid sequences within the putative active site revealed that the $T$. spiralis cyanase harboured all the key amino acids characteristic of a functional protein (Supplementary Fig. S2). To ascertain whether the DNA encodes an operative protein or represents a non-functional pseudogene, the full-length transcript was cloned, expressed and assayed for activity. The purified recombinant protein was found to be biochemically active, generating ammonia in the presence of potassium cyanate and bicarbonate in a dose-dependent manner (Fig. 2A). The activity of the recombinant protein was substantially reduced when incubated with increasing concentrations of $\mathrm{NaCl}$ (Fig. 2C), a known inhibitor of cyanases (Anderson and Little, 1986), or when heated to $95^{\circ} \mathrm{C}$ prior to activity testing (Fig. 2B). Cyanase activity was not observed when a sham protein prepared from an empty vector was assayed in a similar manner (Fig. 2A). Comparative PCR revealed that the cyanase mRNA was produced in all developmental stages studied; mRNA transcripts were dominant in the NBL and ML stages and least abundant in the adult stage (Fig. 3).

Western blots (Fig. 4A) screened with mouse anti-rCYN-1 (c33A) exhibited positive interactions with both the CYN-1 (c94.1) (lane 1) and CYN-1(c33A) (lane 3), but showed no reactivity with protein isolated from cells harbouring the empty vector (lane 2). Lanes containing CWEs displayed multiple bands migrating at apparent molecular masses of 27, 50, 100 and $250 \mathrm{kDa}$. Bands migrating at 27 and $250 \mathrm{kDa}$ were noticeably weaker relative to those migrating at 50 and $100 \mathrm{kDa}$. The functional protein expressed in the pET28a vector [CYN-1(c94.1)] appeared as a singlet migrating at $25 \mathrm{kDa}$, whereas the protein derived from inclusion bodies and expressed as a sumo-fusion protein $[\mathrm{rCYN}-1(\mathrm{c} 33 \mathrm{~A})]$ exhibited multiple immunoreactive 


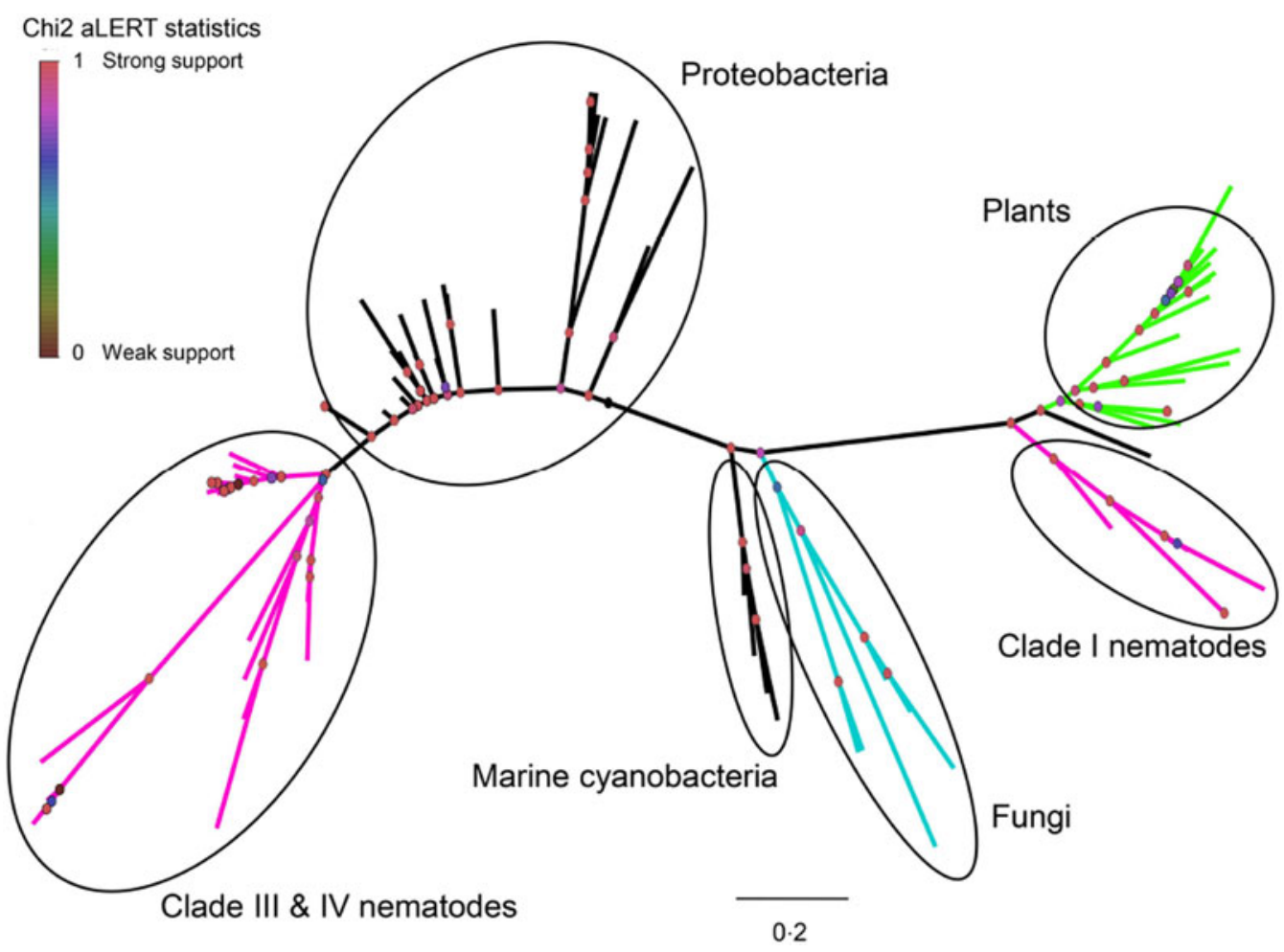

Fig. 1. Unrooted maximum likelihood tree ( $\mathrm{l} n=-8051.23052)$ of cyanase from parasitic nematodes, bacteria, fungi and plants. Cyanase from clade I parasitic nematodes form a monophyletic clade sister to plant cyanases and more closely related to fungal cyanases than to bacterial cyanases. Cyanases from clade III and IV parasitic nematodes cluster with bacterial cyanases. Node support is indicated by the colour within the circle at each node, with red indicating strong support and purple weak support.

bands migrating at 37 and $90 \mathrm{kDa}$, though only a singlet was observed in gels stained with Coomassie blue (Fig. 4B). The molecular mass calculated from the amino acid sequences including vector-derived sequences was $26 \mathrm{kDa}$ (pET28a) and $33 \mathrm{kDa}$ (pSUMO). No classic secretory signal was identified. Immunohistochemical staining of fixed ML tissue sections revealed that antibody binding at 1:800 dilution interacted strongly with the ML hypodermis beneath the cuticle and to a lesser extent with the muscle that lines the hypodermis and cell nuclei within the stichosome (Fig. 5A). No binding was observed to primordial reproductive cells or to tissues of the digestive system (Fig. 5B).

\section{Discussion}

Parasitic nematodes have undergone reductive genome evolution. This has been guided by adaptation to well-defined life cycles, homeostatic buffering of the host and constraints in host range. This phenomenon is no better exemplified than in the genus Trichinella which is characterized by high gene loss (Wang et al., 2012; Zarlenga et al., 2016). Similarities in gene set enrichment and duplications in remaining protein families suggest some overlap in the process of functional adaptation among parasites. However, the number of common protein families in disparate parasitic nematodes is limited and, thereby, consistent with an independent acquisition of parasitism. In the diversification of the genus Trichinella, at least 15 protein domains were born, 13 of which have been annotated to bacterial, viral or fungal origins (Wang et al., 2012). This information suggests that HGT played prominently in the evolutionary process.

Four characters have been proposed as key determinants when validating HGT: (1) extensive phylogenetic analyses; (2) distribution patterns in closely related organisms; (3) physical associations among putative donor and recipient organisms (Andersson, 2005); and (4) longevity and integration of the gene product into the biology of the recipient (Blaxter, 2007). Through evolutionary genome-guided analyses, we previously identified a putative cyanase gene within the parasitic nematode $T$. spiralis (see Zarlenga et al., 2016). Given the gene was expressed most highly in a life stage within host striated muscle cells, the probability of this gene having been derived from contaminating plant or bacterial DNA is minimal. Although a physical association between the lineage giving rise to Trichinella and plants cannot be confirmed from extant organisms, we find no other plausible explanation for the presence of cyanase in Trichinella other than through HGT.

Phylogenetic analyses showed that the cyanase in Trichinella clustered more closely with those derived from plants than with those from bacteria. Monophyly of the Trichinella cyanase with plant cyanases had strong support based on phylogenetic analysis of full-length amino acid sequence datasets, and formed a subclade with other basal clade I nematodes that was sister to the larger plant-based group. This finding contrasts with prior work that holistically linked nematode cyanases to transient bacterial ancestry or to bacterial contamination (Gan et al., 2002; Elleuche and Pöggeler, 2008; Schlachter et al., 2017). The placement of Trichinella spp., Trichuris spp. and S. baturini within a subclade exclusive of plants suggests that the cyanase was acquired once by an ancient common ancestor of all three and passed down to extant taxa. The most recent common ancestor of these genera lived more than 400 million years ago (MYA) (McGill et al., 2017). In contrast, a broader examination of the Phylum Nematoda showed that cyanases among the Secernentea including filarioids, ascaridoids and strongyloids, formed a large monophyletic subclade within the bacterial cyanases. No homologues of cyanase have been identified in the entomopathogenic nematode Romanomermis culicivorax, the only other Adenophorea whose genome has been sequenced. Further, cyanase has neither been observed in free-living nematodes nor in the most recently diverged crown nematodes (clade V). A functional cyanase 
A

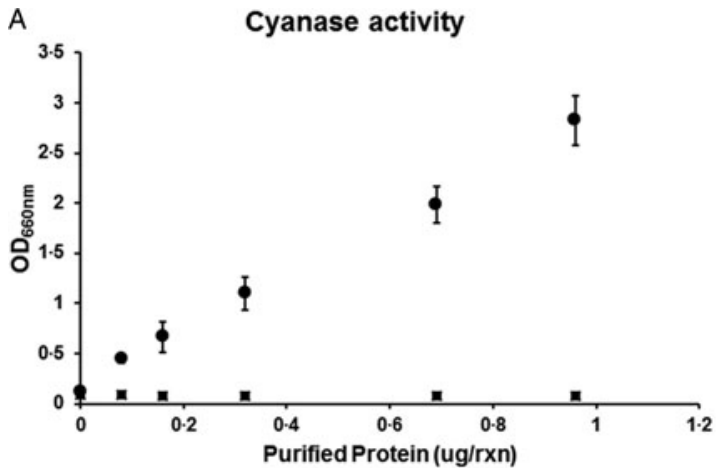

B

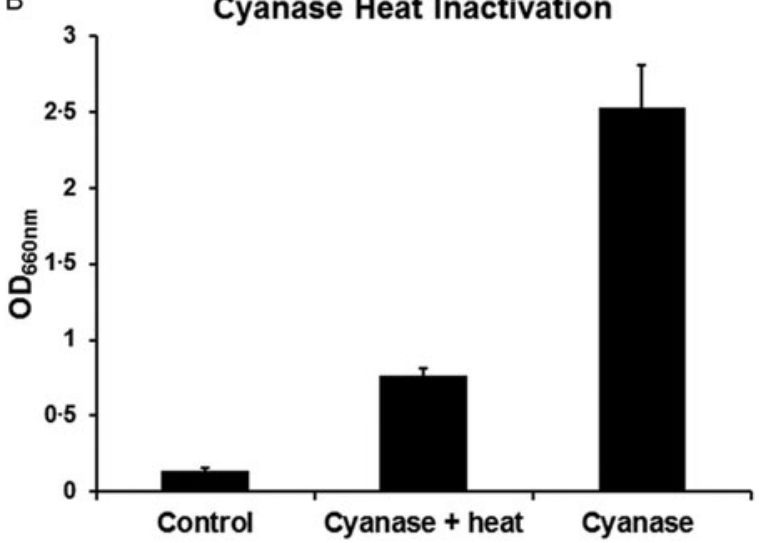

$C_{3.5} \quad$ Cyanase activity vs $[\mathrm{NaCl}]$

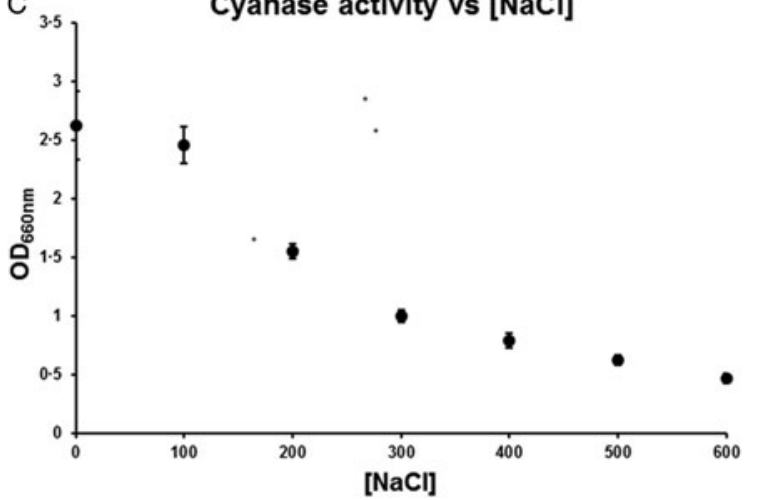

Fig. 2. Activity of $T$. spiralis recombinant cyanase. Affinity purified $\mathrm{rCYN}-1$ (c94.1) was used to assay; (A) cyanase activity $(\bullet)$ relative to affinity purified negative control antigen ( $\square$ ); (B) change in cyanase activity relative to $\mathrm{NaCl}$ concentration $(0-600 \mathrm{~mm}$ ); and $(C)$ change in cyanase activity prior to and following heat inactivation (10 $\mathrm{min}$ $95^{\circ} \mathrm{C}$ ). The control is the reaction in the absence of recombinant protein.

homologue has been identified as a product of HGT in numerous plant ectoparasites, such as the spider mite, Tetranychus urticae, for which data also support acquisition from plants (Wybouw et al., 2012, 2018).

Within the concept of macroevolution, it has been proposed that 'pre-adaptation' (Bock, 1959) is an early step in attaining or developing new structures in an organism. As this concept relates to parasitism, this proposal broadly correlates with the transition of an organism to a new environment or ecotropism. Dieterich and Sommer (2009) hypothesized that the acquisition of detoxifying enzymes must occur during this pre-adaptation phase when a free-living organism transitions to a host environment. The authors cited, as an example, demonstrable increases in numerous detoxifying enzymes in the 'intermediate' necromenic nematode, $P$. pacificus, as precursors to a parasitic life style when compared with the free-living nematode, Caenorhabditis elegans. Evidence has also been presented that $P$. pacificus likely acquired insect-specific diapausin genes via HGT from its

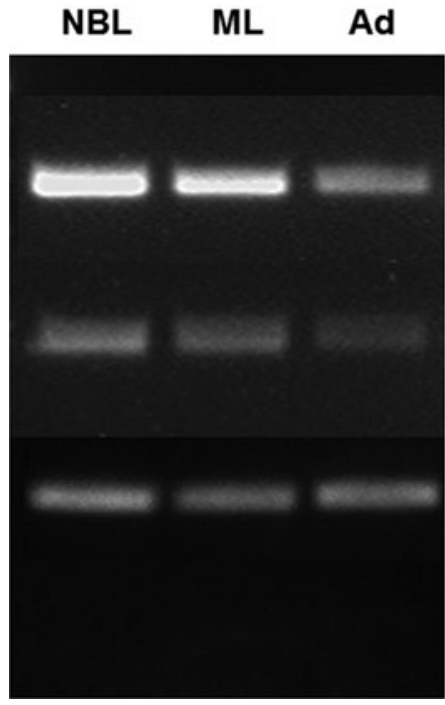

cyanase; 28 cycles

cyanase; 26 cycles

rRNA; 15 cycles

rRNA; 15 cycles (no cDNA synthesis)

Fig. 3. Stage-specific transcription of the $T$. spiralis cyanase gene. Random primerderived CDNA from three developmental stages of $T$. spiralis (ML, NBL and adult) was amplified with cyanase-specific and 18S rRNA-specific primers at the defined cycle numbers. Amplification of rRNA within a total RNA preparation prior to reverse transcription was used as a control for gDNA contamination. Fragments were separated by agarose gel electrophoresis and stained with ethidium bromide. Cycle numbers were experimentally determined to be within the linear portion of the amplification curve. $\mathrm{NBL}=$ newborn larvae; $\mathrm{ML}=$ muscle larvae; $\mathrm{Ad}=$ adult worms .

associations with the scarab beetle (Rödelsperger and Sommer, 2011). This evidence may be directly relevant to the presence of cyanase in Trichinella; however, whether the cyanase of Trichinella currently functions in this capacity, i.e. detoxification, is not yet known. Its unconventional and putative non-bacterial source raised reasonable doubt as to the activity of the cyanase gene of Trichinella and favoured that of an archaic pseudogene. To this end, a recombinant protein was generated from the cloned gene that was bioactive, heat-sensitive and predictably vulnerable to anion inhibitory effects. No activity was observed in the protein column purified from bacteria harbouring an empty vector, indicating that the observed activity was not of bacterial origin. Immunohistochemical staining of ML localized the protein to the epidermis and, to a lesser extent, to the proximal musculature and stichocyte nuclei. This location is consistent with the detoxification of cyanate or metabolites that may permeate the cuticle. However, active gene transcription was observed in all stages of development, including the NBL and ML, which exist within sterile environments, namely circulating blood and muscle cells, respectively. Thus, assuming that transcription equates to the translation of an active protein, functionality in extant organisms is not likely related to detoxification of externally acquired substrate but either to detoxification of internally generated products or to the parasites own metabolic needs. Reduced transcription in fully developed adult worms is consistent with this interpretation. Crisp et al. (2015) discovered that most HGT genes expressed in animals are metabolically related and, during evolution, have likely contributed to a biochemical diversification of the organism.

The decomposition of cyanate by cyanase has been shown important for producing $\mathrm{NH}_{3}$ as an alternative nitrogen source (Kunz and Nagappan, 1989; Anderson et al., 1990) and $\mathrm{CO}_{2}$ for carbon utilization in photosynthetic cyanobacteria (Espie et al., 2007). Given its life cycle, host niche and the ubiquitous transcription profile of Trichinella cyanase, cyanate degradation in extant Trichinella may be linked to pyrimidine or arginine biosynthesis and control of CP-derived cyanate production rather than the detoxification of host or environmentally acquired cyanate. Unlike most organisms, members of the genus Trichinella 
A
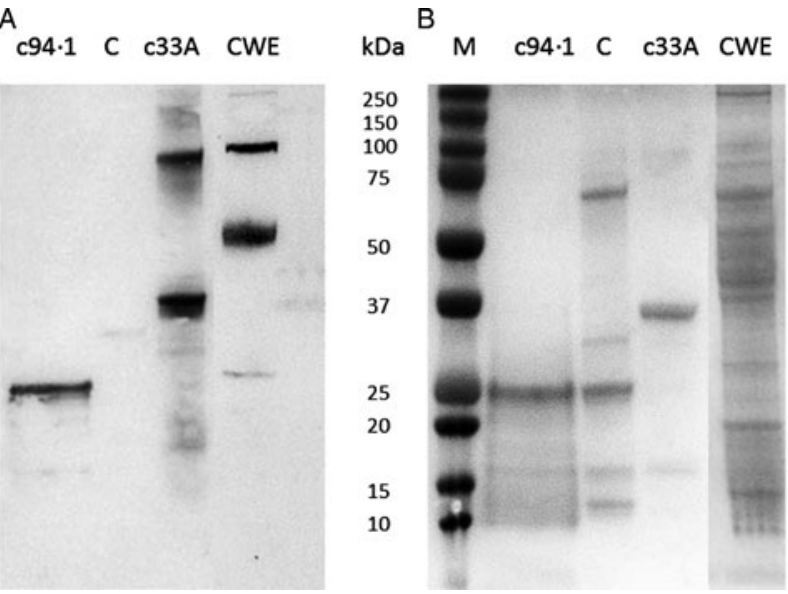

Fig. 4. Western blot of $T$. spiralis cyanase. Affinity-purified rCYN-1(c94.1), rCYN-1(c33A) and ML-CWE were separated on $8-16 \%$ denaturing polyacrylamide gels and either blotted with mouse rCYN-1(c33.A) antisera (gel A) or stained with Coomassie Blue (gel B). Pre-stained molecular weight standards (BioRad) were used as reference.

lack the prototypical CAD protein [CP synthetase 2 (CPS-2), aspartate transcarbamylase and dihydroorotase] that encodes the activities required to initiate pyrimidine biosynthesis. Absence of the CAD protein was also observed in most clade 8 (Spirurina; as defined by Holterman et al., 2006) nematodes that harbour a cyanase gene (Supplementary Table S2). It is possible that the cyanase in these organisms is linked to unutilized substrate in pyrimidine biosynthesis.

Under physiological $\mathrm{pH}$, cyanate is generated as both the primary decomposition product of CP (Guilloton and Karst, 1987) and from the dissociation of urea. In the Trichinella genome (Mitreva et al., 2011), we identified a gene corresponding only to the CPS-2 large subunit; the small subunit of CPS-2 that hydrolyses glutamine neither appeared in the genome nor did separate enzymes encoding aspartate transcarbamylase or dihydroorotase. It is possible that $\mathrm{CP}$ may be generated other than by the reciprocal linkage between the activities on the small and large subunits of the CPS protein from other hydrolytic activity capable of generating glutamate and free ammonia (Hewagama et al., 1999). Precedence exists in nature for the existence of pyrimidine autotrophs primarily in protozoans (el Kouni, 2017). Further, Entamoeba histolytica is capable of de novo pyrimidine synthesis in the absence of the archetypical biosynthetic pathway, even though none of the enzymes required for pyrimidine biosynthesis can be found within the genome (Anderson and Loftus, 2005). A pathway for non-canonical pyrimidine biosynthesis in E. histolytica has not yet been characterized; however, it has been speculated that the pyrimidine degradation pathway might contribute to biosynthesis. Similar findings have been observed in cestodes and filaroids. Other possibilities are salvage pathways used by the parasite to acquire needed pyrimidines from the host. This is particularly interesting, given that parasites such as cestodes, filarids and, of course, Trichinella spp., Trichuris spp. and Soboliphyme spp. all have tissue-dwelling stages during development.

In aqueous solution, urea decomposes to ammonium ions and cyanate which further converts to $\mathrm{CO}_{2}$ and ammonia naturally or through the action of cyanase; however, the urea cycle is absent from most nematode species including Trichinella. Major constituents of Trichinella excretory/secretory products are ammonia and aliphatic amines in the form of methyl-, ethyl-, propyl-, butyl-, amyl- and heptylamine (Haskins and Weinstein, 1957; Gilbert et al., 1973). Ethylenediamine, cadaverine, ethanolamine and 1-amino-2-propanol are also by-products of Trichinella metabolism. The source of these amine products is not known;
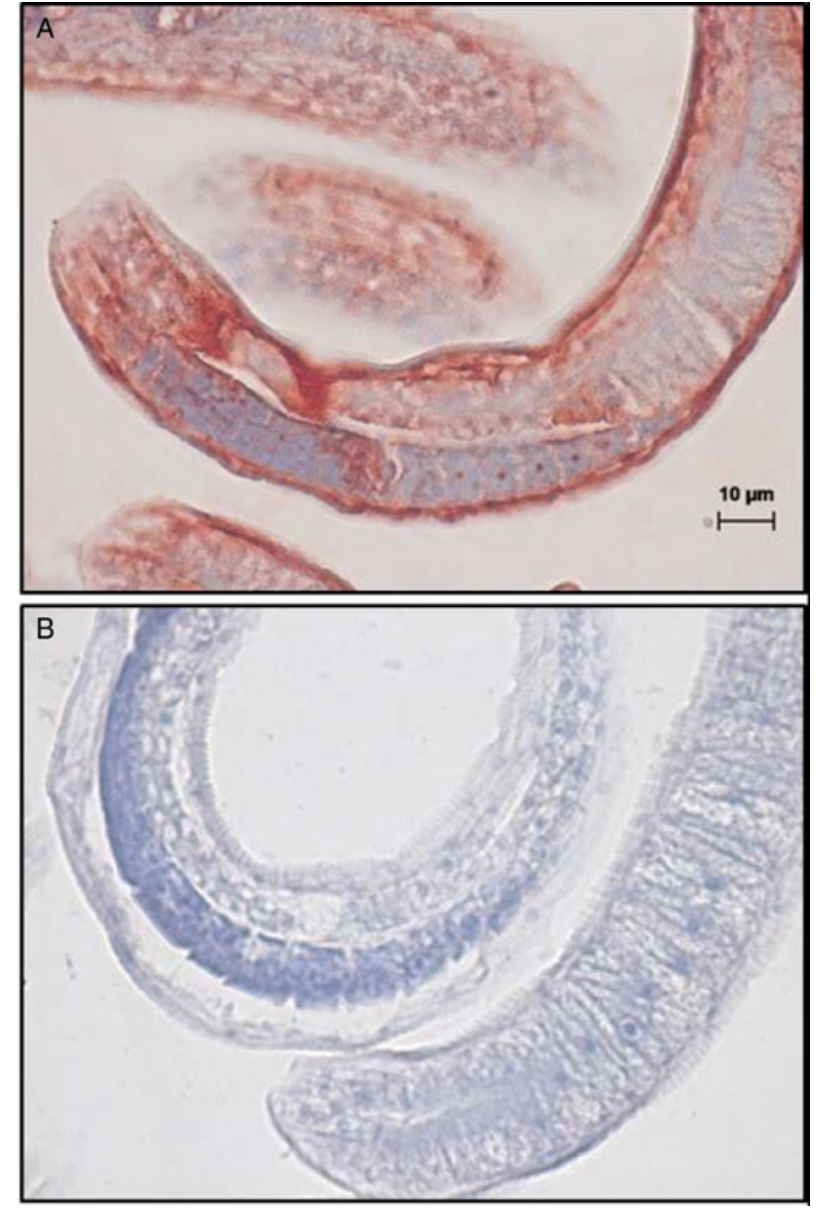

Fig. 5. Immunohistochemical localization of native cyanase in formalin-fixed, paraffin-embedded cross-sections of $T$. spiralis ML. Tissue sections were incubated with (A) mouse anti-rCYN-1 serum (1:800) or (B) a control mouse anti-recombinant Ostertagia apyrase serum (1:600) similarly produced. Antibody binding (red) was visualized by incubation with horseradish peroxidase-labelled anti-mouse IgG followed by Dako AEC substrate. Haematoxylin was used as counter-stain (blue). A scale bar of $10 \mu \mathrm{m}$ is shown.

however, the ammonia likely originates in part, from the failed initial step in the mitochondrial-derived urea cycle because of the absence of CPS-1. It is also possible that cyanate and therefore ammonia are generated from host-acquired CP needed for pyrimidine and arginine biosynthesis via cyanase.

The acquisition of cyanase in clade I nematodes was probably associated with ancestral feeding habits. Trichinella and Trichuris are members of the order Trichinellida, and Soboliphyme belongs to the order Dioctophymatida. If acquired from a single HGT event, this would have occurred before the split, which is estimated to have transpired 400-470 MYA (McGill et al., 2017). In like manner, HGT of the plant-derived spider mite cyanase genes has been projected to have occurred before or shortly after the formation of the Acariformes which was $>435$ MYA (Dabert et al., 2010). These timeframes approximate the period when aquatic plants diverged to embryophytes (land plants) (Sanderson et al., 2004; Rensing et al., 2008; Morris et al., 2018).

Within the clade I ancestry, current information does not differentiate between HGT followed by massive gene loss, or independent acquisition of cyanase followed by lineage-specific divergence. However, within the Phylum Nematoda, HGT of homologous cyanases, from two different Kingdoms is consistent with multiple, independent events. Independent HGT has been observed in cyst and root-knot nematodes in the acquisition of cellulase (Smant et al., 1998) and xylanase (Mitreva-Dautova 
et al., 2006) genes from soil bacterial, and in the transfer of cyanase among some fungi (Elmore et al., 2015). Recently, Danchin et al. (2017) showed that the transcriptomes of the clade I plant ectoparasites Xiphinema index and Longidorus elongates acquired GH12 cellulase from bacteria that may be linked to plant parasitism; however, it is not known whether this was a single or independent acquisition prior to divergence. To date, the acquisition of functionally homologous genes from different Kingdoms has not yet been observed.

In a molecular phylogenetic analysis of the Phylum Nematoda, Holterman et al. (2006) noted that the genus Teratocephalus coincides with secernentean radiation and is comprised predominantly of terrestrial bacterivores. In contrast, nematodes that feed predominantly on fungi are more closely associated with plant parasitic nematodes and support the notion that this group arose from fungivorous ancestors. Given that fungal cyanases form a monophyletic group with closer ties to the early-branching nematodes and plants than to bacteria, an association between the clade I nematodes and fungi cannot be excluded. Alternatively, clade I nematodes may have acquired the cyanase secondarily from a prior plant-fungal association. However, we believe that a delineation in feeding habits and associations among ancestral free-living nematodes account for the acquisition of cyanase from different kingdoms. This raises intriguing questions regarding HGT of cyanase in numerous parasite lineages and the evolution of parasitism.

In conclusion, although it is difficult to ascertain events that took place $>450$ MYA using only extant organisms, strong phylogenetic inference provides a pathway to explore deep evolutionary and ecological history (e.g. Brooks and McLennan, 2002). Current data suggest that the early ancestors of Trichinella had an association with plants. They further indicate that the cyanase within Trichinella is functionally active in all development stages studied to date, suggesting if, at one time, the cyanase was acquired to detoxify environmentally acquired cyanate, this role has changed in extant organisms.

Supplementary material. The supplementary material for this article can be found at https://doi.org/10.1017/S0031182018001701

Financial support. D.S.Z., P.T., W.T. and E.P.H. are funded by the US Department of Agriculture, Agricultural Research Service.

Conflicts of interest. None.

Ethical standards. Not applicable.

\section{References}

Andersson JO (2005) Lateral gene transfer in eukaryotes. Cellular and Molecular Life Sciences 62, 1182-1197.

Anderson PM and Little RM (1986) Kinetic properties of cyanase. Biochemistry 25, 1621-1626.

Anderson IJ and Loftus BJ (2005) Entamoeba histolytica: observations on metabolism based on the genome sequence. Experimental Parasitology 110, 173-177.

Anderson PM, Sung Y-C and Fuchs JA (1990) The cyanase operon and cyanate metabolism. FEMS Microbiology Reviews 7, 247-252.

Blaxter M (2007) Symbiont genes in host genomes: fragments with a future? Cell Host \& Microbe 2, 211-213.

Blaxter M (2011) Nematodes: the worm and its relatives. PLoS Biology 9, e1001050. https://doi.org/10.1371/journal.pbio.1001050.

Blaxter M, Koutsovoulos G, Jones M, Kumar S and Elsworth B (2014) Phylogenomics of Nematoda. In Cotton J, Hughes J and Olson P (eds), Next-generation Systematics. Cambridge, UK: Cambridge University Press, pp. 62-83. https://doi.org/10.1017/CBO9781139236355.004.

Bock WJ (1959) Preadaptation and multiple evolutionary pathways. Evolution 13, 194-211.
Brooks DR and McLennan DA (2002) The Nature of Diversity: An Evolutionary Voyage of Discovery. Chicago, USA: University of Chicago Press.

Crisp A, Boschetti C, Perry M, Tunnacliffe A and Micklem G (2015) Expression of multiple horizontally acquired genes is a hallmark of both vertebrate and invertebrate genomes. Genome Biology 16, 50.

Dabert M, Witalinski W, Kazmierski A, Olszanowski Z and Dabert J (2010) Molecular phylogeny of acariform mites (Acari, Arachnida): strong conflict between phylogenetic signal and long-branch attraction artifacts. Molecular Phylogenetics and Evolution 56, 222-241.

Dagan T, Artzy-Randrup Y and Martin W (2008) Modular networks and cumulative impact of lateral transfer in prokaryote genome evolution. Proceedings of the National Academy of Sciences, USA 105, 10039-10044.

Dame JB, Murrell KD, Worley DE and Schad GA (1987) Trichinella spiralis: genetic evidence for synanthropic subspecies in sylvatic hosts. Experimental Parasitology 64, 195-203.

Danchin EGJ, Perfus-Barbeoch L, Rancurel C, Thorpe P, Da Rocha M, Bajew S, Neilson R, Guzeeva ES, Da Silva C, Guy J, Labadie K, Esmenjaud D, Helder J, Jones JT and den Akker SE (2017) The transcriptomes of Xiphinema index and Longidorus elongatus suggest independent acquisition of some plant parasitism genes by horizontal gene transfer in early-branching nematodes. Genes (Basel) 8, E287.

Dieterich C and Sommer RJ (2009) How to become a parasite - lessons from the genomes of nematodes. Trends in Genetics 25, 203-209.

Dieterich C, Clifton SW, Schuster LN, Chinwalla A, Delehaunty K, Dinkelacker I, Fulton L, Fulton R, Godfrey J, Minx P, Mitreva M, Roeseler W, Tian H, Witte H, Yang SP, Wilson RK and Sommer RJ (2008) The Pristionchus pacificus genome provides a unique perspective on nematode lifestyle and parasitism. Nature Genetics 40, 1193-1198.

Ebbs S (2004) Biological degradation of cyanide compounds. Current Opinion in Biotechnology 15, 231-236.

el Kouni MH (2017) Pyrimidine metabolism in schistosomes: a comparison with other parasites and the search for potential chemotherapeutic targets. Comparative Biochemistry and Physiology. Part B, Biochemistry \& Molecular Biology 213, 55-80.

Elleuche S and Pöggeler S (2008) A cyanase is transcriptionally regulated by arginine and involved in cyanate decomposition in Sordaria macrospora. Fungal Genetics and Biology 45, 1458-1469.

Elmore MH, McGary KL, Wisecaver JH, Slot JC, Geiser DM, Sink S, O'Donnell K and Rokas A (2015) Clustering of two genes putatively involved in cyanate detoxification evolved recently and independently in multiple fungal lineages. Genome Biology and Evolution 7, 789-800.

Espie GS, Jalali F, Tong T, Zacal NJ and So AK (2007) Involvement of the cynABDS operon and the $\mathrm{CO} 2$-concentrating mechanism in the lightdependent transport and metabolism of cyanate by cyanobacteria. Journal of Bacteriology 189, 1013-1024.

Gan YH, Chua KL, Chua HH, Liu B, Hii CS, Chong HL and Tan P (2002) Characterization of Burkholderia pseudomallei infection and identification of novel virulence factors using a Caenorhabditis elegans host system. Molecular Microbiology 44, 1185-1197.

Gilbert A, Castro J, Ferguson JD and Gorden C (1973) Amine excretion in excysted larvae and adults of Trichinella spiralis. Comparative Biochemistry and Physiology. Part A, Molecular \& Integrative Physiology 45, 819-828.

Guilloton M and Karst F (1987) Cyanate specifically inhibits arginine biosynthesis in Escherichia coli K12: a case of by-product inhibition? Journal of General Microbiology 133, 655-665.

Guindon S, Dufayard JF, Lefort V, Anisimova M, Hordijk W and Gascuel O (2010) New algorithms and methods to estimate Maximum-Likelihood phylogenies: assessing the performance of PhyML 3.0. Systematic Biology 59, 307-321.

Haegeman A, Jones JT and Danchin EGJ (2011) Horizontal gene transfer in nematodes: a catalyst for plant parasitism? Molecular Plant-microbe Interactions 24, 879-887.

Haskins WT and Weinstein PP (1957) Nitrogenous excretory products of Trichinella spiralis larvae. Journal of Parasitology 43, 19-24.

Hewagama A, Guy HI, Vickrey JF and Evans DR (1999) Functional linkage between the glutaminase and synthetase domains of carbamoyl-phosphate synthetase. Role of serine 44 in carbamoyl-phosphate synthetase-aspartate carbamoyltransferase-dihydroorotase (cad). The Journal of Biological Chemistry 274, 28240-28245.

Holterman M, van der Wurff A, van den Elsen S, van Megen H, Bongers T, Holovachov O, Bakker J and Helder J (2006) Phylum-wide analysis of SSU 
rDNA reveals deep phylogenetic relationships among nematodes and accelerated evolution toward crown clades. Molecular Biology and Evolution 23, 1792-1800.

Kamennaya NA and Post AF (2013) Distribution and expression of the cyanate acquisition potential among cyanobacterial populations in oligotrophic marine waters. Limnology and Oceanography 58, 1959-1971.

Keeling PJ and Palmer JD (2008) Horizontal gene transfer in eukaryotic evolution. Nature Reviews. Genetics 9, 605-618.

Keen NT and Roberts PA (1998) Plant parasitic nematodes: digesting a page from the microbe book. Proceedings of the National Academy of Sciences, USA 95, 4789-4790.

Kunz DA and Nagappan O (1989) Cyanase-mediated utilization of cyanate in Pseudomonas fluorescens. Applied and Environmental Microbiology 55, 256-258.

Maeda S and Omata T (2009) Nitrite transport activity of the ABC-type cyanate transporter of the cyanobacterium Synechococcus elongatus. Journal of Bacteriology 191, 3265-3272.

Marti HP, Murrell KD and Gamble HR (1987) Trichinella spiralis: immunization of pigs with newborn larval antigens. Experimental Parasitology 63, 68-73.

McGill LM, Fitzpatrick DA, Pisani D and Burnell AM (2017) Estimation of phylogenetic divergence times in Panagrolaimidae and other nematodes using relaxed molecular clocks calibrated with insect and crustacean fossils. Nematology 19, 899-913.

Mitreva M, Smant G and Helder J (2009) Role of horizontal gene transfer in the evolution of plant parasitism among nematodes. Methods in Molecular Biology 532, 517-535.

Mitreva M, Jasmer DP, Zarlenga DS, Wang Z, Abubucker S, Martin J, Taylor CM, Yin Y, Fulton L, Minx P, Yang SP, Warren WC, Fulton RS, Bhonagiri V, Zhang X, Hallsworth-Pepin K, Clifton SW, McCarter JP, Appleton J, Mardis ER and Wilson RK (2011) The draft genome of the parasitic nematode Trichinella spiralis. Nature Genetics 43, 228-235.

Mitreva-Dautova M, Roze E, Overmars H, de Graaff L, Schots A, Helder J, Goverse A, Bakker J and Smant G (2006) A symbiont-independent endo-1,4-beta-xylanase from the plant-parasitic nematode Meloidogyne incognita. Molecular Plant-microbe Interactions 19, 521-529.

Morris JL, Puttick MN, Clark JW, Edwards D, Kenrick P, Pressel S, Wellman CH, Yang Z, Schneider H and Donoghue PCJ (2018) The timescale of early land plant evolution. Proceedings of the National Academy of Sciences, USA 115, E2274-E2283.

Nishikawa BK, Fowlkes DM and Kay BK (1989) Convenient uses of polymerase chain reaction in analyzing recombinant cDNA clones. Biotechniques 7 , 730-735.

Opperman CH, Bird DM, Williamson VM, Rokhsar DS, Burke M, Cohn J, Cromer J, Diener S, Gajan J, Graham S, Houfek TD, Liu Q, Mitros T, Schaff J, Schaffer R, Scholl E, Sosinski BR, Thomas VP and Windham E (2008) Sequence and genetic map of Meloidogyne hapla: a compact nematode genome for plant parasitism. Proceedings of the National Academy of Sciences, USA 105, 14802-14807.

Polz MF, Alm EJ and Hanage WP (2013) Horizontal gene transfer and the evolution of bacterial and archaeal population structure. Trends in Genetics 29, 170-175.

Rensing SA, Lang D, Zimmer AD, Terry A, Salamov A, Shapiro $\mathrm{H}$, Nishiyama T, Perroud PF, Lindquist EA, Kamisugi Y, Tanahashi T, Sakakibara K, Fujita T, Oishi K, Shin-I T, Kuroki Y, Toyoda A, Suzuki Y, Hashimoto S, Yamaguchi K, Sugano S, Kohara Y, Fujiyama A, Anterola A, Aoki S, Ashton N, Barbazuk WB, Barker E,
Bennetzen JL, Blankenship R, Cho SH, Dutcher SK, Estelle M, Fawcett JA, Gundlach H, Hanada K, Heyl A, Hicks KA, Hughes J, Lohr M, Mayer K, Melkozernov A, Murata T, Nelson DR, Pils B, Prigge M, Reiss B, Renner T, Rombauts S, Rushton PJ, Sanderfoot A, Schween G, Shiu SH, Stueber K, Theodoulou FL, Tu H, Van de Peer Y, Verrier PJ, Waters E, Wood A, Yang L, Cove D, Cuming AC, Hasebe M, Lucas S, Mishler BD, Reski R, Grigoriev IV, Quatrano RS and Boore JL (2008) The Physcomitrella genome reveals evolutionary insights into the conquest of land by plants. Science 319, 64-69.

Richards TA, Dacks JB, Jenkinson JM, Thornton CR and Talbot NJ (2006) Evolution of filamentous plant pathogens: gene exchange across eukaryotic kingdoms. Current Biology 16, 1857-1864.

Rödelsperger C and Sommer RJ (2011) Computational archaeology of the Pristionchus pacificus genome reveals evidence of horizontal gene transfers from insects. BioMed Central Evolutionary Biology 11, 239.

Sanderson MJ, Thorne JL, Wikstrom N and Bremer K (2004) Molecular evidence on plant divergence times. American Journal of Botany 91, 16561665.

Schlachter CR, Klapper V, Wybouw N, Radford T, Van Leeuwen T, Grbic M and Chruszcz M (2017) Structural characterization of a eukaryotic cyanase from Tetranychus urticae. Journal of Agricultural and Food Chemistry 65, 5453-5462.

Smant G, Stokkermans JP, Yan Y, de Boer JM, Baum TJ, Wang X, Hussey RS, Gommers FJ, Henrissat B, Davis EL, Helder J, Schots A and Bakker J (1998) Endogenous cellulases in animals: isolation of beta-1, 4-endoglucanase genes from two species of plant-parasitic cyst nematodes. Proceedings of the National Academy of Sciences, USA 9, 4906-4911.

Walsh MA, Otwinowski Z, Perrakis A, Anderson PM and Joachimiak Andrzej A (2000) Structure of cyanase reveals that a novel dimeric and decameric arrangement of subunits is required for formation of the enzyme active site. Structure 8, 505-514.

Wang Z, Zarlenga D, Martin J, Abubucker S and Mitreva M (2012) Exploring metazoan evolution through dynamic and holistic changes in protein families and domains. BioMed Central Evolutionary Biology 12, 138.

Wybouw N, Balabanidou V, Ballhorn DJ, Dermauw W, Grbić M, Vontas J and Van Leeuwen T (2012) A horizontally transferred cyanase gene in the spider mite Tetranychus urticae is involved in cyanate metabolism and is differentially expressed upon host plant change. Insect Biochemistry and Molecular Biology 42, 881-889.

Wybouw N, Dermauw W, Tirry L, Stevens C, Grbić M, Feyereisen R and Van Leeuwen T (2014) A gene horizontally transferred from bacteria protects arthropods from host plant cyanide poisoning. eLIFE 3, e02365.

Wybouw N, Van Leeuwen T and Dermauw W (2018) A massive incorporation of microbial genes into the genome of Tetranychus urticae, a polyphagous arthropod herbivore. Insect Molecular Biology 27, 333-351.

Zarlenga DS, Boyd P, Lichtenfels JR, Hill D and Gamble HR (2002) Identification and characterisation of a cDNA sequence encoding a glutamic acid-rich protein specifically transcribed in Trichinella spiralis newborn larvae and recognised by infected swine serum. International Journal for Parasitology 32, 1361-1370.

Zarlenga DS, Nisbet AJ, Gasbarre LC and Garrett WM (2011) A calcium-activated nucleotidase secreted from Ostertagia ostertagi 4th-stage larvae is a member of the novel salivary apyrases present in blood-feeding arthropods. Parasitology 138, 333-343.

Zarlenga D, Wang $\mathbf{Z}$ and Mitreva $\mathbf{M}$ (2016) Trichinella spiralis: adaptation and parasitism. Veterinary Parasitology 231, 8-21. 